Popović, G. S., Lazarević, S. (2021): Skadar Lake cultural landscape and architectural heritage-Potential for the Development of Fisheries and Rural Tourism. Agriculture and Forestry, 67(1): 255-269.

DOI: 10.17707/AgricultForest.67.1.21

Svetislav G. POPOVIĆ , Slađana LAZAREVIĆ $^{2}$

\title{
SKADAR LAKE CULTURAL LANDSCAPE AND ARCHITECTURAL HERITAGE Potential for the Development of Fisheries and Rural Tourism
}

\begin{abstract}
SUMMARY
The settlement of Vranjina is situated on a slope in the eastern part of the island of the same name, on the northern belt of Skadar Lake in Montenegro. With its exceptional historical and cultural values, protected natural heritage and partly preserved architectural heritage of vernacular architecture, this settlement is just one of many examples in the Skadar Lake National Park, with specific potential for rural tourism development. The Skadar Lake basin is rich in diverse ambience, which is reflected in organically developed landscapes and associative cultural landscapes through the Charter on the International Recognition of Cultural Landscapes. The results of the research, based on years of urban and architectural research in the Skadar Lake area by the authors, indicate the possibility of reviving the tradition of fishing, as an important branch of agriculture, as a contribution not only to sustainable agriculture, but also to protection and valorization of architectural heritage and traditional fishermen's houses on the Skadar Lake.
\end{abstract}

Keywords: cultural landscape, rural tourism, Skadar Lake, fisheries, sustainable agriculture, heritage

\section{INTRODUCTION}

Revitalization of the villages and sustainable valorization of the settlements of Skadar Lake, along with the preservation of the landscape are the basis for the development of rural tourism in this region of Montenegro. The cultural landscape of Skadar Lake and its surroundings formed by a significant number of real properties has not been valorized, which has resulted in permanent devastation and degradation. The non-valorized segment of cultural heritage comprises cultural landscapes, rural ensembles, groups and structures, fortifications - the system of Austro-Hungarian and other fortifications and structures of old mills, bridges and roads.

\footnotetext{
${ }^{1}$ Svetislav G. Popovic (corresponding author: svetislav@ac.me), University of Montenegro, Faculty of Architecture, Podgorica, MONTENEGRO.

${ }^{2}$ Sladjana Lazarevic, University of Montenegro, Faculty of Architecture, Podgorica, MONTENEGRO

Notes: The authors declare that they have no conflicts of interest. Authorship Form signed online.

Recieved:11/01/2021

Accepted:20/03/2021
} 
Stanojevic and Vasic (1975), in the book History of Montenegro (Book Three, From the Beginning of the $16^{\text {th }}$ to the End of the $17^{\text {th }}$ Century, Volume One), describe Skadar Lake from the Ottoman Empire as the most important economic basin of Montenegro: "...The second and most important economic basin of Skadar Lake, unusually rich in fish, and mostly in bleak, which has been exported in large quantities to Venice and other Italian cities since the beginning of the $16^{\text {th }}$ century... At an earlier time, $400-500$ boats made of hollowed out logs could be seen on the lake. Endless flocks of sea ducks, which were believed to be heralds of a good catch, would simply cover the sky, like black clouds." These citations precisely speak of the fishing tradition which, in addition to agriculture in fertile fields that were not so flooded at the time, brought significant income to the local population, which would be an example of sustainable agricultural development today.

In order to preserve the cultural landscape, authentic biodiversity and landscape, either by bringing back the traditional boats or introducing alternative modes of lake transport without the use of fossil fuels in the area of Skadar Lake National Park (Lazarević, 2016), preconditions would be created for the development of ecological rural tourism which will attract environmentally aware tourists, lovers of tradition and culture, especially after the COVID-19 pandemic.

Therefore, this paper points out all the potentials and limitations for the development of rural tourism through the activation of fisheries, as an important traditional branch of agriculture, protection of biodiversity and cultural landscape, and restoration of architectural heritage in order to create necessary preconditions for a comprehensive development of Skadar Lake.

\section{MATERIAL AND METHODS}

An exceptional group of cultural settlements comprises traditional folk architecture, old uninhabited or sparsely populated and neglected fishing villages situated on the Lake shores - Radus, Krnjice, Poseljani, Karuc, Dodosi, and other once inhabited villages where people used to live on fishing and untangle their nets. Therefore, it must not be allowed for the cultural goods which were previously recognized and placed under protection by the Law to be treated as the settlement of Vranjina which was placed under protection by the Law on 9 January 1979, when its significance was accepted, and which was soon after left to urbanization pressures, uncontrolled development and incompliance (Gakovic, 2013). Precisely using the example of the settlement of Vranjina, as a settlement protected by the Law on Protection of Cultural Heritage for more than 30 years, this paper will point out the potentials for the development of fisheries and rural tourism and all the limitations mostly caused by human interventions in previous decades. The villages around the lake suffer loss in their old look and beauty, traditional shape and function every day. This was especially intensified after the earthquake in 1979, when entire villages with old houses, local churches and other buildings were destroyed in this area. The reconstruction of the damaged villages was carried out relatively quickly, although spontaneously, without any 
professional indicators and controls, so in many cases it was not possible to take into account the preservation of old national values found on the damaged buildings.

In order to better explain the scientific issue, through a presentation of the historical genesis of the settlement, both primary and secondary sources were extensively reserached and reviewed, but also the graphic drawings by the authors of the paper are presented. The methodology relies on analytical research of extensive material within the sub-topic of the paper: Functional spatial potentials and limitations of houses on the Skadar Lake for the development of traditional fisheries and rural tourism and links with modern sustainable development strategies with an emphasis on sustainable agriculture.

\section{RESULTS AND DISCUSSION}

\section{Historical Genesis and Urban Planning Layout of the Settlement of Vranjina}

The age of the settlement cannot be reliably determined. There are no clear indications and evidence of the existence of a settlement in the pre-Ottoman period, which is partly a consequence of the physical and geographical characteristics (Figure 1) of the island which provides no strong basis for living, other than its suitabile location for fishing.

According to records, the oldest building on the island was the Vranje Monastery, that is the Monastery of St. Nicholas of Vranje built in 1223 by Bishop Hilarion (Radusinovic, 1964).

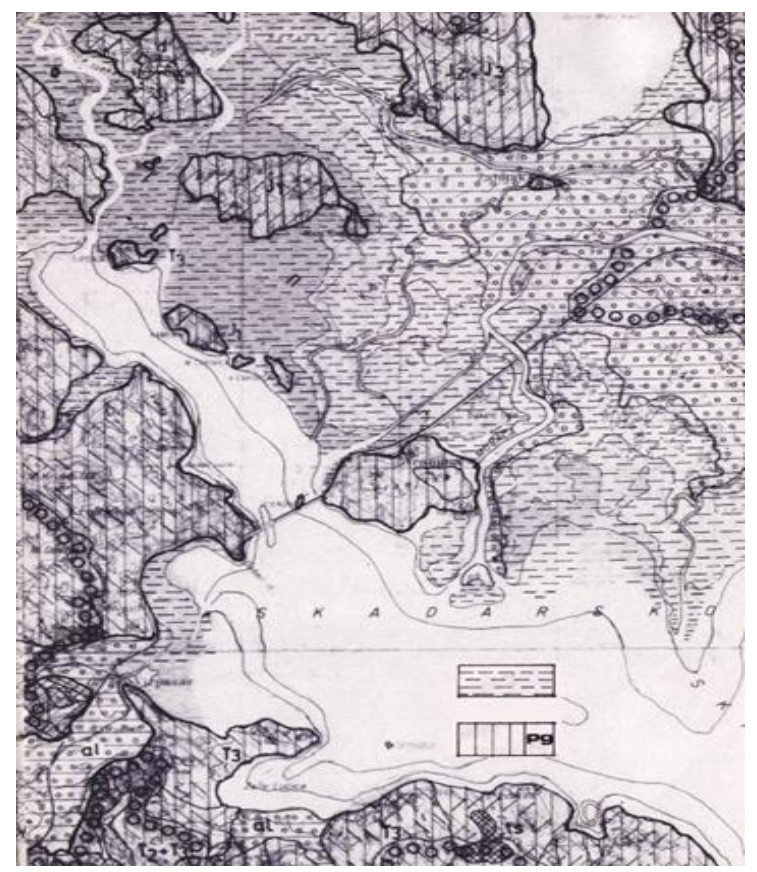

Figure 1. The Skadar Lake Geological Map Board (Spatial Purpose Plan National Parc Skadar Lake, RZUP, 1999) 


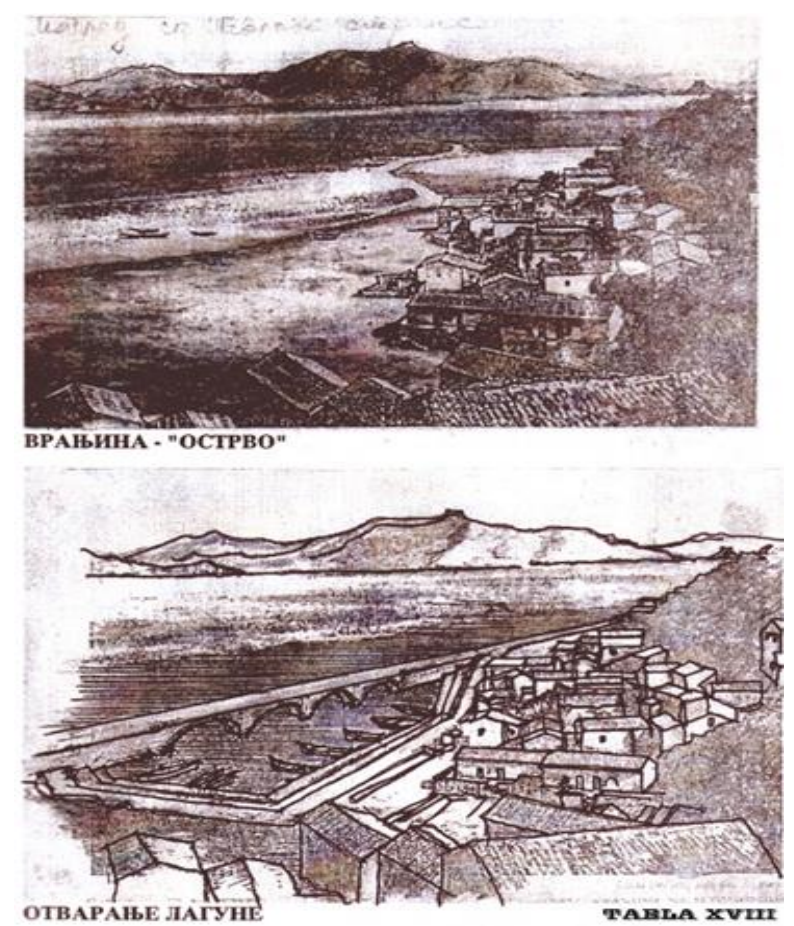

Figure 2. Urban Genesis of the Island of Vranjina, drawings by Vukota Vukotic (1998)

The majority of inhabitants came to the island during the Turkish rule. The reasons were very heterogeneous: escape from blood feuds, exile from the fraternity, fight against the Turks ... which led to a unique example of a community with so many represented fraternities and tribes. Then, approximately 350 years ago, the first houses were built after the island had been bought by the Turks ("families from the Pocek, Dapcevic, Gazivoda, Buskovic, Pajovic, Sjekloca...brotherhoods") (Radusinovic, 1964).

The settlement itself is of compact type, which is imposed both by the terrain and a routine way of life of the locals. The small bay which rises abruptly into the hill after approximately 30 meters conditioned the seemingly spontaneous arrangement of houses, and there is some truth in this, nevertheless. The houses are mostly placed perpendicular to the isohypses, which maximally saves space and scarce arable land (Figure 2). There are also houses that are parallel to the isohypses - this is usually the case with ground floor houses.

There is no spatial accent, if the settlement itself is not taken as such, or a particular centre of the settlement, as in other Skadar settlements - around the springs or cisterns ("gustijerna" - private cistern for the collection of stormwaters). Everything is so intertwined and interconnected with nature that only the bay can be regarded as the settlement centre, with boats which were once 
the only means of transport or "freight animals", through waterways cut into European Bladdernut and Water Chestnut (thick wetland vegetation).

The building itself, using the slope of the terrain and placed directly on the isohypses, is predestinated to be on "two storeys" (on two floors) where, due to the terrain characteristics (Figure 3), the ground floor is much smaller than the first floor which is also the core of the house, the space where people live their lives, despite the limitations imposed by nature, for the purpose of its survival.
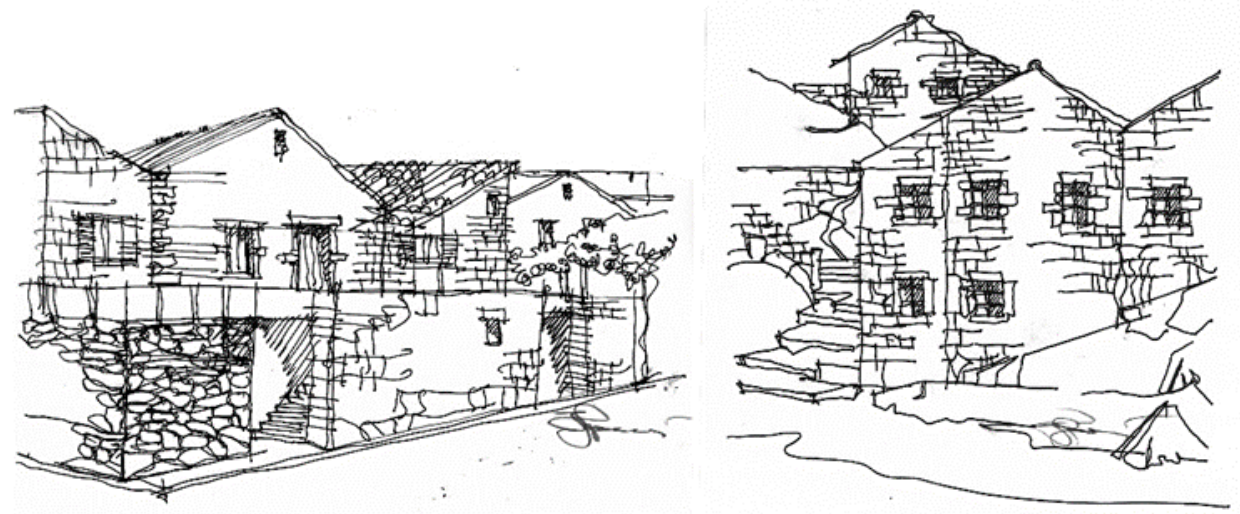

Figure 3. Two-storey house, Vranjina, drawings by S.G. Popovic (1978)

The causes for the settlement of the island significantly influenced the way of living; the house itself with narrow openings was a real small fortress, if necessary, and the compactness of the settlement made it possible to provide common resistance. Locals fished in groups in order to be close at hand in case of an attack on an open lake. The catch was divided into equal parts, assistance was jointly provided to the poor and everyone acted jointly against the Turks (Radusinovic, 1964).

All this indicates the possibility of reviving the tradition of fishing, as an important branch of agriculture, in response not only to sustainable agricultural development, but also to the protection and valorization of architectural heritage, traditional fishing houses on the Skadar Lake. The revival of the villages and settlements of the Skadar Lake, along with the preservation of the cultural landscape, is the basis for the development of rural tourism in this region of Montenegro. With the need to introduce alternative forms of lake transport without the use of fossil fuels and in order to preserve the cultural landscape of the Skadar Lake National Park, preconditions would be created for the development of ecological rural tourism which will attract environmentally aware tourists, lovers of tradition, especially after the COVID-19 pandemic.

\section{Functional Spatial Potentials and Limitations of Houses on the Skadar Lake for the Development of Traditional Fisheries and Rural Tourism}

As for the functional layout, the course of evolution is very noticeable. Starting from a single space in which all existential functions are performed, 
which characterizes the older buildings, via the addition of a new room with a separate entrance to the original space, in order to "improve living standards" as it would be referred to today (Figure 4), to the most widespread type of houses in the settlement of Vranjina - a house with two rooms, a kitchen or "cook house" with a fireplace ("bell-shaped oven"), as the center of the house, and a bedroom or "chamber, room" which, although mostly larger in size, serves only to meet the need specified in its very name (Figure 4).

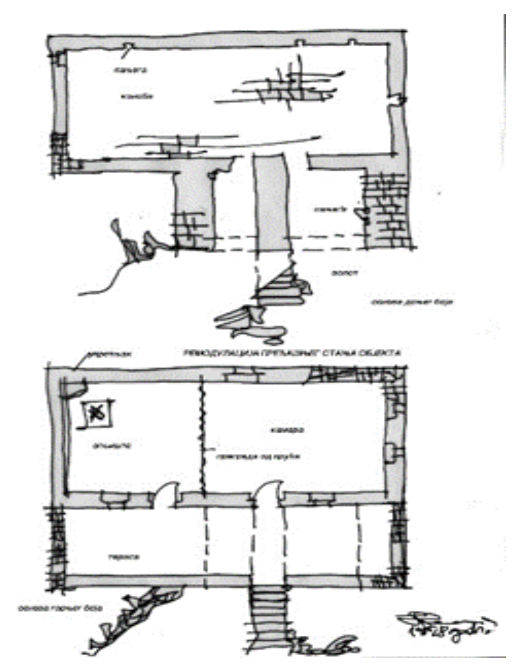

Figure 4. House, typology 1930, drawings by S. G. Popovic (1978)

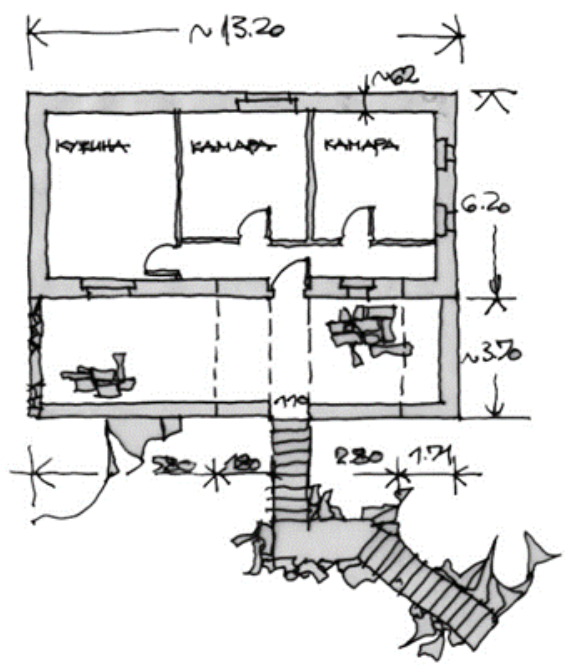

Figure 5. House, typology 1960, drawings by S. G. Popovic (1978) 
Later on, houses are characterized by somewhat more complex content. The number of rooms is increasing. In most cases an entrance hall is added to separate the kitchen and the bedroom; it is also used for storing everyday clothing and footwear and adding a new part of the house to the existing one, with a change of use of rooms (Figure 5).

Storey buildings (Figure 6) retain the same characteristics on the first floor, while the ground floor, as a much smaller area due to terrain constraints, is mainly used for "economic needs", livestock accommodation, fishing tools (Figure 7), storage and drying of food.

The functions of a kitchen or "cook house" are not only to prepare and consume meals; it is also used for the entire daily life of a family. This is because, in addition to two or three beds which are usually there, not including those that may be in the kitchen, items of value that the family owns are kept and exhibited there, starting from pictures of sons and daughters, who mostly live in the city, to various dinner sets, handicrafts and valuables.

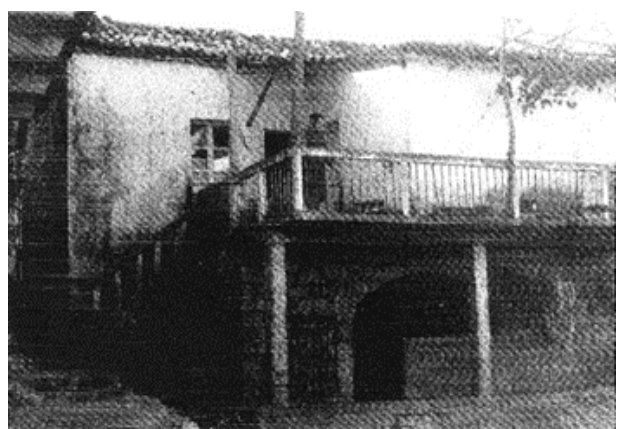

Figure 6. House on a storage room, photo by S.G.Popovic, 1978
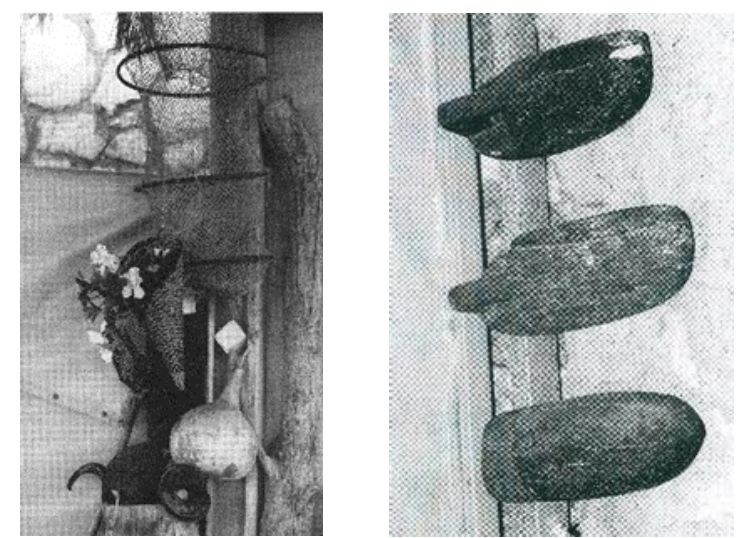

Figure7. Interior of a chamber (picture to the left) and molds for overshoes (picture to the right), photo by S.G.Popovic, 1978 
Basement, pantry, storage for boats - all these are examples of using the room under the above-mentioned primary parts of the building. The room is as wide as the building, though considerably narrower, and its function depends on the occupation of family members.

Due to the presence of a large number of people from different tribes and fraternities, during its genesis the settlement developed no cultural specificity that would characterize a certain way of life or belonging to a special ethnological background.

Each local brought certain habits and peculiarities, and the influence of the proximity of the Coast (Figure 8) is indisputable.
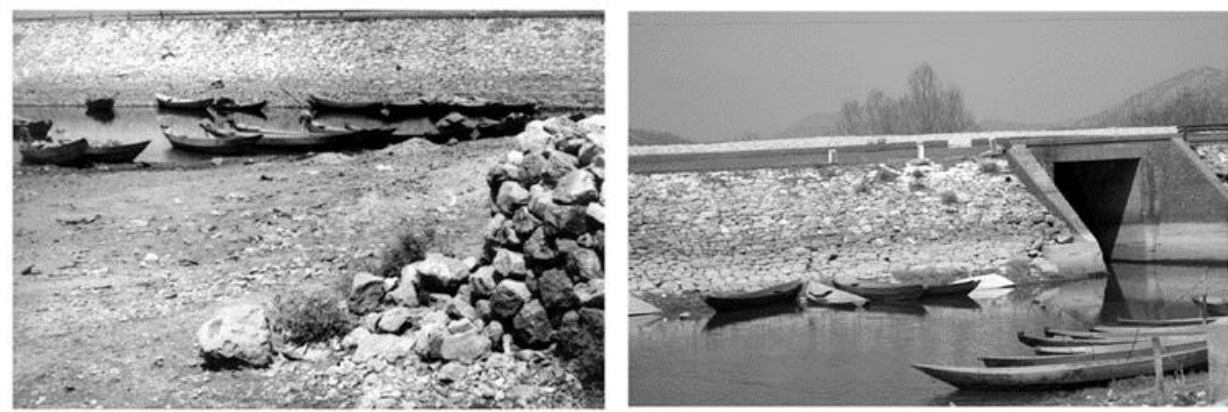

Figure 8. Indigenous boat for transporting bulky goods, $7 \mathrm{~m}$ long, $1 \mathrm{~m}$ wide and $0.5 \mathrm{~m}$ high, photos by S.G.Popovic, 1978

These facts indicate all the limitations of the settlement of Vranjina when it comes to a longer stay in order to meet the needs of housing, but also the advantages of the geographical location of the settlement on the road between the Capital City and the Coast.

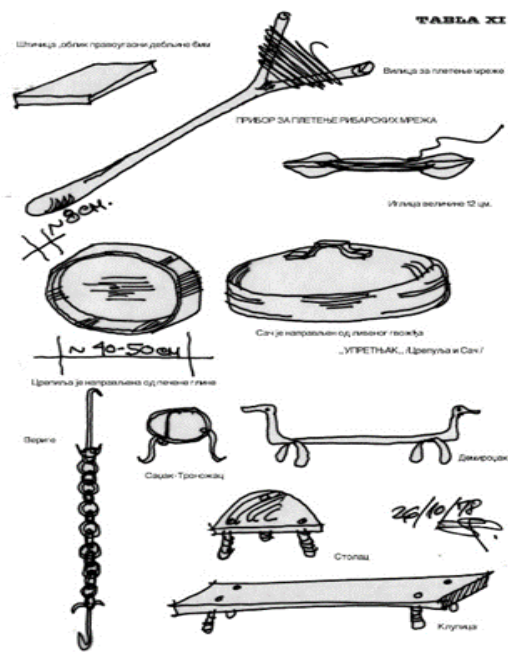

Figure 9. Tools for making fishing nets, chains, pottery, drawing by S.G. Popovic 
On the other hand, these spatial and functional limitations of houses can be a potential for quick and easy revitalization of settlements and revival of rural tourism with traditional fishing (Figure 9).

Architecture is an eternal human concern and passion, the culmination of which is experienced exactly today. In an era of dynamism, hectic life, digitalization and rapid socio-economic changes, people seem to lose selfconfidence and nostalgically turn to the past seeking solace in it. The same goes for architecture which, in the conditions of today's inhumanity, neglect of the built and natural heritage and neglect of traditions, tries to find its meaning in looking back.

However, looking back to what preceded us, certain things are noticed which made the common name "house" invaluable from an architectural point of view as well. Dilapidated, indistinctive, unattractive dwellings offer a real wealth of elements, gained through many years of experience through the life of a building and people in it.

Humanity, harmony, proportions, harmony with nature - that is why it was worth turning back. The configuration of the terrain, vegetation, natural conditions, tradition and mentality of the people, local customs and culture - all this is unconsciously embedded in an inconspicuous stone shape to which the farmers or peasants are connected more and more intimately than the city residents are connected to their architectural apartments equipped with all the wonders of white ware and comfort of living. This is because it is the home where they "came into the world, where they feast and mourn and from where they will be taken out dead."

This retrospective, compared to the present time, confirms the values that are the input for the development of rural tourism, the importance of preserving the cultural landscape and landscape, the need of tourists or visitors for a strong connection with nature and the natural. In addition, this retrospective is supported by the determination of the State, as a declared ecological State, to take care of the natural and built cultural heritage, as well as the adopted development strategies of Montenegro.

\section{Montenegro's Strategic Commitments to Develop Sustainable Agriculture and Food Value Chain as a Basis for the Development of Sustainable Rural Tourism}

The National Strategy for Sustainable Development until 2030 was adopted in 2016 (Ministry of Sustainable Development and Tourism, Government of Montenegro, 2016), while the Smart Specialization Strategy until 2024 recognized agriculture (with an emphasis on the protection of endangered and endemic plant and animal species) as one of the three priority vertical strategic areas (sustainable agriculture and the food value chain), along with sustainable and health tourism and energy and sustainable environment, which 
indicates the additional importance of the development of rural tourism in the upcoming years.

Agriculture is a sector that plays a multiple role in the development of society and economy of Montenegro. Its economic importance is reflected in high contribution to GDP creation (more than 7\%, while accounting for about $2 \%$ at the EU level). There is even greater share of agriculture in the employment of the labour force, since almost one fourth of the total number of employed people in Montenegro are engaged in family farms. In addition, agriculture plays other important roles as well: it constitutes the basis for the food value chain (food industry and related sectors); it contributes to the development of tourism; it encourages the development of many other sectors (production of equipment, machinery and packaging material, transport and numerous services); it is crucial in the sustainable development and mitigation of the depopulation of rural areas; it contributes to the fight against poverty in rural areas and it is an important factor in preserving tradition and the overall cultural heritage of the Montenegrin villages (Ministry of Science, Government of Montenegro, 2019, Smart Specialization Strategy of Montenegro 2019-2024)

The contribution of tourism to rural development is important if the local population participates in its development. It is also a means of protecting the environment, economic and cultural and historical traditions, local culture, etc. (Gasic et al., 2015).

Agriculture is marked by high complementarity with other priority sectors, especially with tourism as the driver of all types of agritourism and health tourism through the presentation of traditional gastronomy in the context of the tourist offer. Also, the sustainable development of the sector mitigates the negative demographic trends, contributes to the balance in territorial development, enables the inclusion of different groups and contributes to the mitigation of the consequences of climate change (Ministry of Science, Government of Montenegro, 2019, Smart Specialization Strategy of Montenegro 2019-2024)

Historically, definition of the term rural meant something located outside the city walls. Viewed from the economic aspect, it can be said that rural means a territory used for food production, while according to the sociological aspect rural means an environment characterized by strong backwardness in relation to technological and cultural development, which is more noticeable in urban areas (Milic, 2011).

On the one hand, rural development plays a significant role from the aspect of socio-economic development of each country, while on the other hand, rural development has a significant role from the aspect of environmental protection as an environment in which the population of a country lives. This indicates the need for strategic care for the preservation of traditional architecture and systematic and planned renovation of houses on the Skadar Lake, with previous detailed architectural research, in order to develop rural tourism and include this valuable UNESCO-recognized area of the National Park for the purpose of 
completing the tourist offer throughout the territory of Montenegro and creating the preconditions for the development of cross-border cooperation in this field with Albania (development of fishery and aquaculture products, in a traditional architectural house of the Skadar Lake). Rural areas directly depend both on the environmental resources and natural landscape that provides great opportunities for rural and urban population.

Rural tourism creates conditions for satisfying the needs of an increasing number of tourists that seek a healthy life-style and experiences that imply pleasure in nature, traditional cuisine, hospitality of husbandries/households in rural areas, enjoyment in tradition and preserved customs and other authentic experiences (Ministry of Sustainable Development and Tourism, The Program of Rural Tourism Development of Montenegro, 2019).

Adequate protection and care of cultural heritage and landscape are key to the further development of cultural tourism in the rural areas, especially to their connection with peri-urban and urban heritage. Settlement patterns and its dichotomy with its cultural and environmental peculiarity have a direct impact on an agrarian landscape and further development of rural tourism (Fikfak, A., Popovic, G.S. \& Kosanovic, S., 2015 and Konjar, M., Kosanović, S., Popović, S.G. and Fikfak, A., 2018).

Given the additional confrontation with the crisis during the COVID-19 pandemic, in the upcoming period special attention should be paid to the management of rural cultural tourism in response to the recovery from the pandemic, considering that numerous studies already confirm that tourist demand will be focused on escape from the urban and salvation in the rural areas. There are many discussion and researches on the topic of rural development as economy driver for tourism sector in post COVID-19 recovery of countries, mainly analysed for territory of China, giving that the recovery of the entire economy, including tourism, is evident only in the territory of Asia, while the rest of the world is still struggling with one of the biggest global crises (UNWTO, 2020).

\section{Cultural Landscape Preservation as Part of the Rural Tourism Strategy}

The concept of a cultural landscape is a variable and multifaceted category which has been differently defined and investigated over the last decades in a number of natural, social and humanistic sciences. The value of cultural landscape (Figure 10) is based on authenticity and autochthony, representativeness (relict, endemism and rarity), biological and geological diversity, abundance of natural phenomena and processes, functional uniqueness, age, aesthetic value and conservation, sustainable development in a global context.

At the same time, landscape is a perfect complex of living environment and territorial arrangement, and it is equivalent to a set of functions of general interest and in different fields (culture, ecology, environment, society); it is also an important economic resource whose sustainable management can directly create new jobs and indirectly affect the improvement of living standards and the 
achievement and promotion of human rights. Cultural landscape is vital for a more human life of people and sustainable development of the society as a whole (Ministry of Sustainable Development and Tourism, Strategy for the Development of Cultural Tourism of Montenegro with an action plan until 2023, 2018). Today's concept of cultural landscape includes the characteristics of natural area, as well as the forms enforced on physical space due to human activities, the physical structure of space and cultural order. This symbolic appropriation of territory transforms the physical environment into a cultural landscape, which is by definition building culture out of a certain territory (Munarriz, 2007).

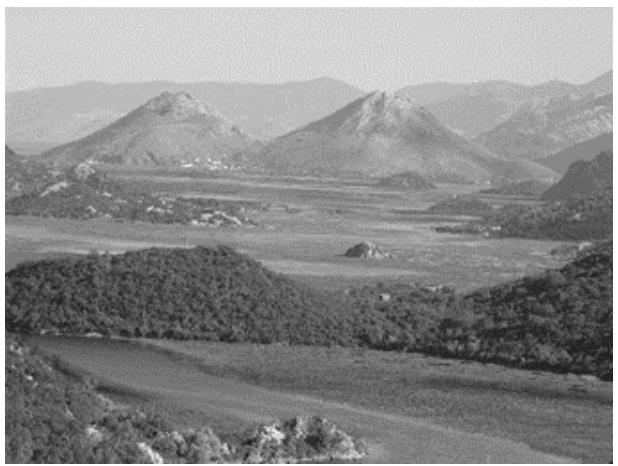

Figure 10. Landscape of the Skadar Lake, photo by S.G. Popović, 2000

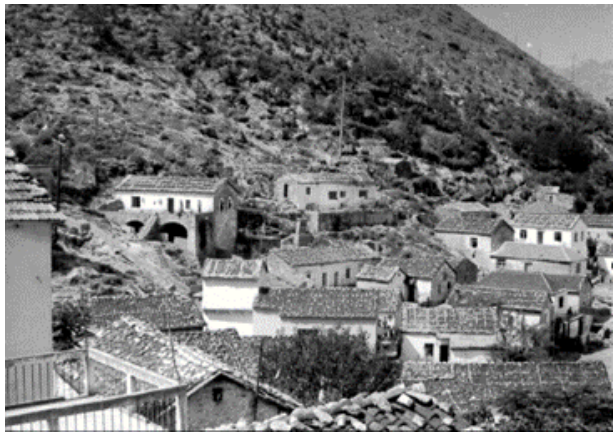

Figure 11. Landscape of Vranjine settlement, photo by S.G. Popović, 1978

Inconsistency in terminology can be noticed in the literature belonging to different scientific disciplines, so that in parallel with the term cultural landscape, the terms cultivated landscape, anthropogenic landscape, can also be found, while some researchers make a connection with the Marxist concept of 'humanized' nature. The modern notion of cultural landscape indicates a great diversity of physical and associative relations, the most important of which is the relation of the population (inhabitants) towards the territory they inhabit and its natural elements.

It is impossible to separate the cultural landscape from the architectural environment (Figure 11 and Figure 12). On the contrary, insisting on an 
integrated approach contributes to the growing importance of the whole area, the authentic values of the man-made landscape, as well as other categories of cultural heritage as a resource for sustainable development. Landscape development reflects the development of civilization, its level, social organization and climatic characteristics as the most important precondition for the survival of ecosystems (Figure 13).

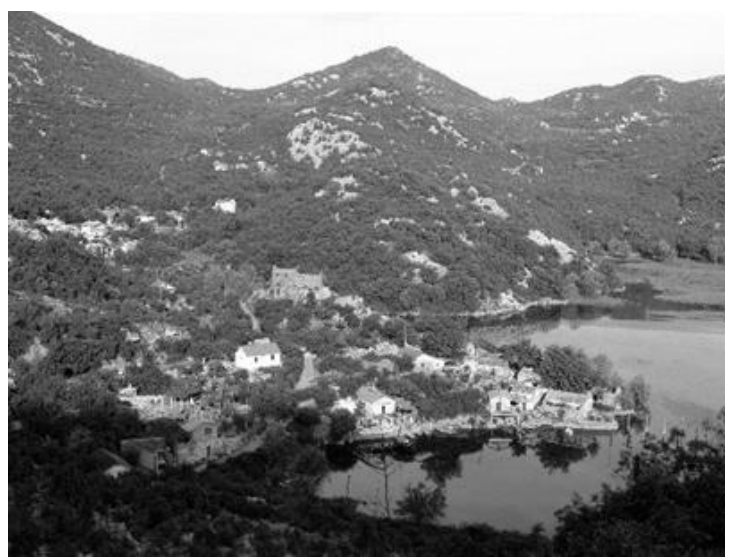

Figure 12. Karuc fishing village, photo by S.G. Popovic, 2000

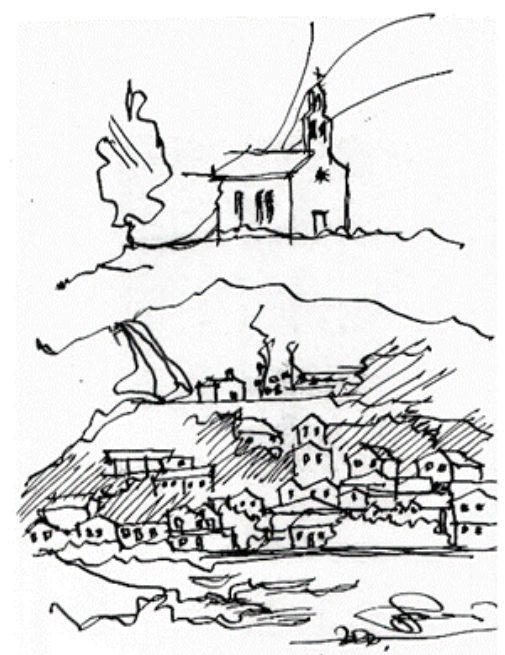

Figure 13. Vranjina Settlement, drawings by S.G. Popovic, 2006

\section{CONCLUSIONS}

Research by the former Ministry of Science, conducted for the purpose of developing the Smart Specialization Strategy, identified approximately 40 companies engaged in the processing of meat, dairy products, vegetables and fruits, herbs and aromatic plants and mushrooms, production of honey, olive oil, 
potato and cereals, fisheries and aquaculture (Ministry of Science, Government of Montenegro, 2019). However, the exact number of fishing companies is unknown. A cluster of ponds has been identified; however traditional fishermen remain in the shadow of development. It is precisely through the development of rural tourism that the settlement of Vranjine, as well as a number of other settlement structures and villages on the Skadar Lake, including the most famous fishing village of Karuc, can be renewed and traditional fishing can be revived, giving local residents a chance to earn income by strengthening the economy of the whole country.

In 2011, the National Location Study of Vranjina with Lesendro was developed, which defines these sites as follows: Relying, together with Virpazar, on the basic infrastructural direction of Podgorica-Adriatic Sea, Vranjina has a significant development chance. Formed on the island, as a fishing settlement of a compact type, Vranjina is today connected to the mainland, but it still remains an attractive settlement, with interesting potentials.

Located on the island of the same name, with an extremely interesting settlement structure directly leaning on the Lake, Vranjina is planned as one of the entry points to the Park, from the direction of Podgorica. In addition to the settlement itself, specific values are the monastery complex, the National Park building and the island fortress Lesendro. The picturesque ambience and the convenience of the traffic position are the basis for the development of transit and excursion tourism, through the construction of well-designed hospitality and trade facilities, related to the main activity of the settlement - fishing. The planned accommodation capacities are envisaged within the settlement itself, then in the Monastery dormitory and on the site next to the existing building of the National Park. The specific building of the Lesendro fortress is intended for events and hospitality activities (Gakovic, 2013).

Rural tourism is an interaction of agricultural production, presentation of tradition, traditional gastronomy and tourist services, in a word, the use of existing resources. Rural tourism is recognised in the Spatial Plan for the Special Purpose of the National Park Skadar Lake (Ministry of Sustainable Development and Tourism, 2018), but further steps have yet to be identified. Therefore, the development of rural tourism should be based on the principles of sustainable development, through the revitalization of existing, traditional buildings or heritage, to which a new purpose is given - the tourist one. Rural tourism (especially farm tourism) is therefore an essential part of the overall, sustainable development (Ministry of Agriculture and Rural Development of Montenegro, Program for the Development of Agriculture and Rural Areas in Montenegro under IPARD II -2014-2020).

In order to create infrastructural preconditions for the development of rural tourism, it is necessary to: 
- Revalorize the overall architectural heritage and provide adequate protection, all in accordance with the Law on Protection of Cultural Heritage of Montenegro;

- Carry out a research on the impact of climate change on floods, and organize coastal areas with a cascading profile that will ensure the usability of platforms in front of houses during frequent floods; and,

- Carry out a detailed research, bio-mapping and engineering with the aim of preserving biodiversity and economic valorisation of the biological potential of the autochthonous flora and fauna of the Skadar Lake.

\section{REFERENCES}

Fikfak, A., Popovic, G.S. \& Kosanovic, S. (2015): Settlement patterns in an agrarian landscape -principles of classification in Goriska Brda, Slovenia. Agriculture and Forestry, 61 (4), 319-335

Gakovic, Z. (2013): The State of Cultural Heritage of Montenegro, p. 48-49, 129

Gasic, M. (2015): The Impact of Rural Tourism on Local Economic Development" Ecologica 22, 77: 32-36

Konjar, M., Kosanović, S., Popović, S.G. and Fikfak A (2018): Urban/Rural Dichotomy and the Forms-In-Between, Sustainability and Resilience Socio-Spatial Perspective. Editors Alenka Fikfak, Saja Kosanović, Miha Konjar and Enrico Anguillari. Publisher TU Delft Open, Caitriona McArdle, Architectural Copyeditor, Dublin

Lazarević, S., Janjušević J. (2016): Are Investments in Sustainable Transportation in Tourism Sector Economically Justified, Journal of US-China Public Administration, Vol. 13, No. 7, 472-482 doi: 10.17265/1548-6591/2016.07.005

Milic, B. (2011): Rural Development: Practicum for Local Actors, Belgrade: Standing Conference of Towns and Municipalities

Ministry of Agriculture and Rural Development of Montenegro (2015): Program for the Development of Agriculture and Rural Areas in Montenegro under IPARD II 2014-2020

Ministry of Science, Government of Montenegro (2019): Smart Specialization Strategy of Montenegro 2019-2024

Ministry of Sustainable Development and Tourism (2016): National Strategy of Sustainable Development of Montenegro until 2030. Podgorica, Montenegro (available at http://www.mrt.gov.me/odrzivi/165045/Obavjestenje-Nacionalnastrategija-odrzivog-razvoja-do-2030-godine.html)

Ministry of Sustainable Development and Tourism (2019): The Program of Rural Tourism Development of Montenegro, Government of Montenegro, Podgorica

Ministry of Sustainable Development and Tourism (2018): Spatial Plan for the Special Purpose of the National Park Skadar Lake

Ministry of Sustainable Development and Tourism (2018): Strategy for the Development of Cultural Tourism of Montenegro with an action plan until 2023

Munárriz, Á. (2007): The Cultural Landscape Concept. AIBR: Revista de Antropología Iberoamericana 6, 65

Popović, G.S. (2007), Architectural heritage of the Skadar Lake basin, GTZ, Podgorica Radusinovic, D. (1964): Skadar Lake and the Peripheral Belt, Graphic Institute, Titograd RZUP, Vukotić, V. (1999): Spatial Purpose Plan National Parc Skadar Lake, Podgorica 
Stanojević, G., Vasić, M. (1975): History of Montenegro (Book Three, From theBeginning of the 16th to the End of the 17th Century, Volume One)

UNWTO, World Tourism Organization (2020): World Tourism Barometer, vol. 18, No.

5, August/September 2020, Madrid, https://doi.org/10.18111/wtobarometereng 